\title{
Biza Walker: cinco espécies novas do Brasil (Hemiptera, Cicadellidae, Neocoelidiinae) ${ }^{1}$
}

\author{
Larissa de Bortolli Chiamolera ${ }^{2} \&$ Rodney R. Cavichioli ${ }^{2}$
}

${ }^{1}$ Contribuição número 1415 do Departamento de Zoologia, Universidade Federal do Paraná.

${ }^{2}$ Departamento de Zoologia, Universidade Federal do Paraná. Caixa Postal 19020, 81531-980 Curitiba, Paraná, Brasil. Bolsista do CNPq. E-mail: larissachiamolera@bol.com.br, cavich@ufpr.br

\begin{abstract}
Biza Walker: five new Brazilian species (Hemiptera, Cicadellidae, Neocoelidiinae). In the present study five new species of Biza are presented: $B$. castanea sp. nov., $B$. ocellata sp. nov., $B$. maculata sp. nov., $B$. trimaculata (all from Brazil, Amazonas State) and B. similis sp. nov. (from Brazil, Mato Grosso State). The new species of Biza can be distinguished by the aspect of the male genitalia, mainly by the shape of the aedeagus, the presence or absence of process in the aedeagus and shape of pygofer.
\end{abstract}

KEY WORDS. Biza, Cicadellidae, Hemiptera, Neocoelidiinae, new species.

Neocoelidiinae tem apenas 19 gêneros conhecidos, sendo pouco estudada, tanto no Brasil como nos demais países da América do Sul. Nielson \& KNigTh (2000) sugeriram que os Neocoelidiinae tiveram sua origem na região Neotropical, possivelmente durante o início do Cretáceo.

Além de Oman (1943), que criou a subfamília, poucos pesquisadores estudaram este grupo, destacando apenas KRAMER (1958, 1959, 1961, 1962, 1964, 1967) e Kramer \& LinNAVuori (1959) que descreveram vários gêneros e espécies e realizou várias revisões de Neocoelidiinae.

WALKer (1858) descreveu Biza, designando como espécietipo B. crocea Walker, 1858. Segundo Kramer (1962) é um gênero relacionado com Megacoelidia Kramer \& Linnavuori, 1959, do qual se diferencia, principalmente pelo tamanho: em Biza, as cigarrinhas atingem de 7 a $8 \mathrm{~mm}$, enquanto que, em Megacoelidia, estas atigem $13 \mathrm{~mm}$ ou mais; a coroa é achatada em Biza e distintamente côncava em Megacoelidia. KRAMER (1964) chama atenção que os espécimes de Biza apresentam uma notável semelhança no aspecto geral com as dormas de cercopídeos.

Kramer (1962) descreveu mais duas espécies: B. chinai do Brasil (Pará) e B. craspa da Costa Rica e KrAmer (1967) descreveu uma outra espécie: B. ava do Panamá. Chiamolera \& CAVICHIOLI (1999) propuseram uma outra espécie: Biza sinopensis, do Mato Grosso, Brasil. Atualmente o gênero conta com cinco espécies, sendo que no presente trabalho são propostas mais cinco: Biza castanea sp. nov., $B$. ocellata sp. nov., $B$. similis sp.nov., $B$. maculata sp. nov. e B. trimaculata sp. nov.

Os espécimes estudados estão depositados na "Coleção de Entomologia Pe. Jesus Santiago Moure" do Departamento de Zoologia da Universidade Federal do Paraná (DZUP) e na coleção do Instituto Nacional de Pesquisas da Amazônia (INPA).
As técnicas para o exame das genitálias de machos seguem aquelas propostas por OMAN (1949), com pequenas alterações e a terminologia adotada na descrição das espécies a de KRAMER (1964), exceto para os escleritos faciais que seguem Hamilton (1981) e Mejdalani (1998). As medidas são fornecidas em milímetros.

\section{Biza castanea sp. nov. Figs 1-8}

Holótipo macho. Brasil, Amazonas: Coari, Rio Urucu, Petrobrás, RUC-30, 07-14/IX/1992, P.F. Bührnheim \& N. O. Aguiar col. [INPA].

Diagnose. Cabeça com duas pequenas manchas marrons na base da coroa. Pigóforo com um dente ventral e ápice pontiagudo e edeago com dois longos processos látero-apicais.

Holótipo macho. Comprimento total 10,48; comprimento mediano da cabeça: 0,76 ; distância transocular 1,84; distância interocular 1,04; comprimento mediano do pronoto 1,08 ; distância transumeral 2,72; largura máxima do escutelo 1,92; comprimento mediano do escutelo 1,80; comprimento das asas anteriores 8,28; largura máxima das asas anteriores 2,68.

Cabeça, em vista dorsal, com comprimento mediano 3/7 da largura transocular; margem anterior levemente angulada, com uma carena na transição entre a coroa e a face; superfície lisa; ocelos pouco diferenciados, localizados na margem entre a coroa e a face, acima dos lóbulos supra-antenais; lóbulos supraantenais não protuberantes dorsalmente e, em vista lateral, carenados e oblíquos; fronte, em vista lateral, levemente arqueada com superfície levemente pontuada; clípeo, em vista lateral, contínuo com a fronte e em vista frontal de aspecto retangular. 


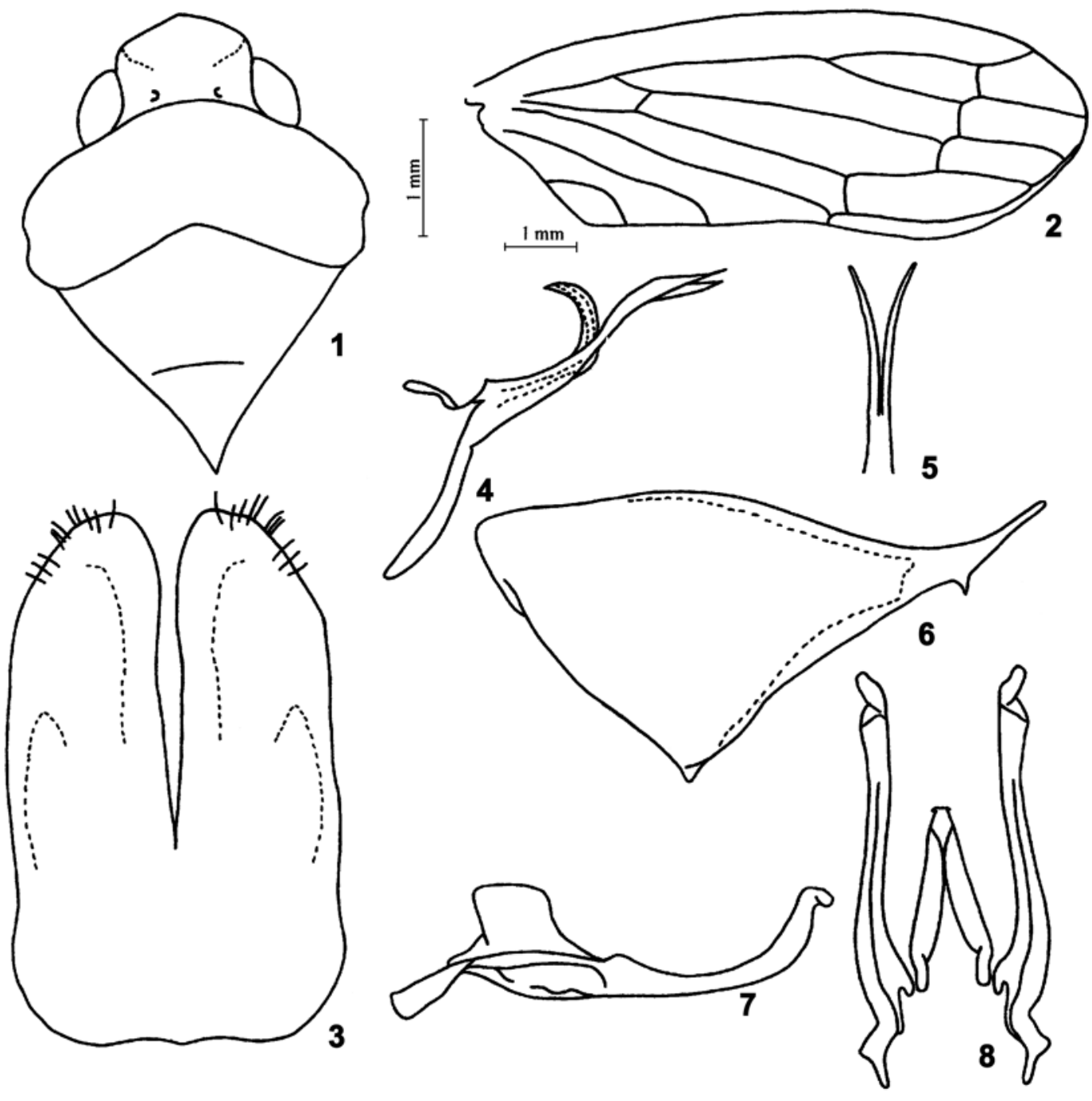

Figs 1-8. Biza castanea sp. nov.: (1) cabeça, pronoto e escutelo, vista dorsal; (2) placas subgenitais, vista ventral; (3) pigóforo, vista lateral; (4) processo lateral do edeago, vista dorsal; (5) edeago, vista lateral; (6) estilos e conetivo, vista dorsal; (7) estilo, vista lateral; (8) asa anterior.

Pronoto mais largo que a cabeça, margem anterior arredondada e a posterior com uma reentrância mediana; as láteroanteriores convergentes e as látero-posteriores divergentes anteriormente; superfície levemente enrugada. Escutelo com superfície pontuada. Asas anteriores com venação distinta, com quatro células apicais e três anteapicais, somente a célula anteapical externa fechada; presença de um curto e estreito apêndice que se estende até a base da terceira célula apical.

Genitália masculina. Pigóforo com ápice afilado e pontiagudo, margem ventral com um dente no terço apical. Placas subgenitais fusionadas apenas basalmente e, em vista lateral, com dente dorsal apical e com microcerdas no ápice. Estilos relativamente compridos, com gancho apical e, em vista lateral, com lobo largo projetado dorsalmente no terço basal.
Conetivo em forma de " $Y$ " invertido. Edeago com expansão dorsal mediana e uma curvatura no terço apical da haste central; com um par de processos laterais saindo do terço apical.

Fêmea desconhecida.

Coloração geral castanha. Cabeça com duas pequenas manchas escuras na base da coroa. Asas anteriores castanhoclaras com as veias castanhas, exceto apicalmente, onde as veias são marrons.

Comentários. Biza castanea sp. nov. é similar a $B$. crocea Walker, 1858 e B. chinai Kramer, 1962 diferindo pelo aspecto da genitália do macho, principalmente pelo processo do edeago que é relativamente maior e mais apical e pelo pigóforo que apresenta o ápice mais pontiagudo. 


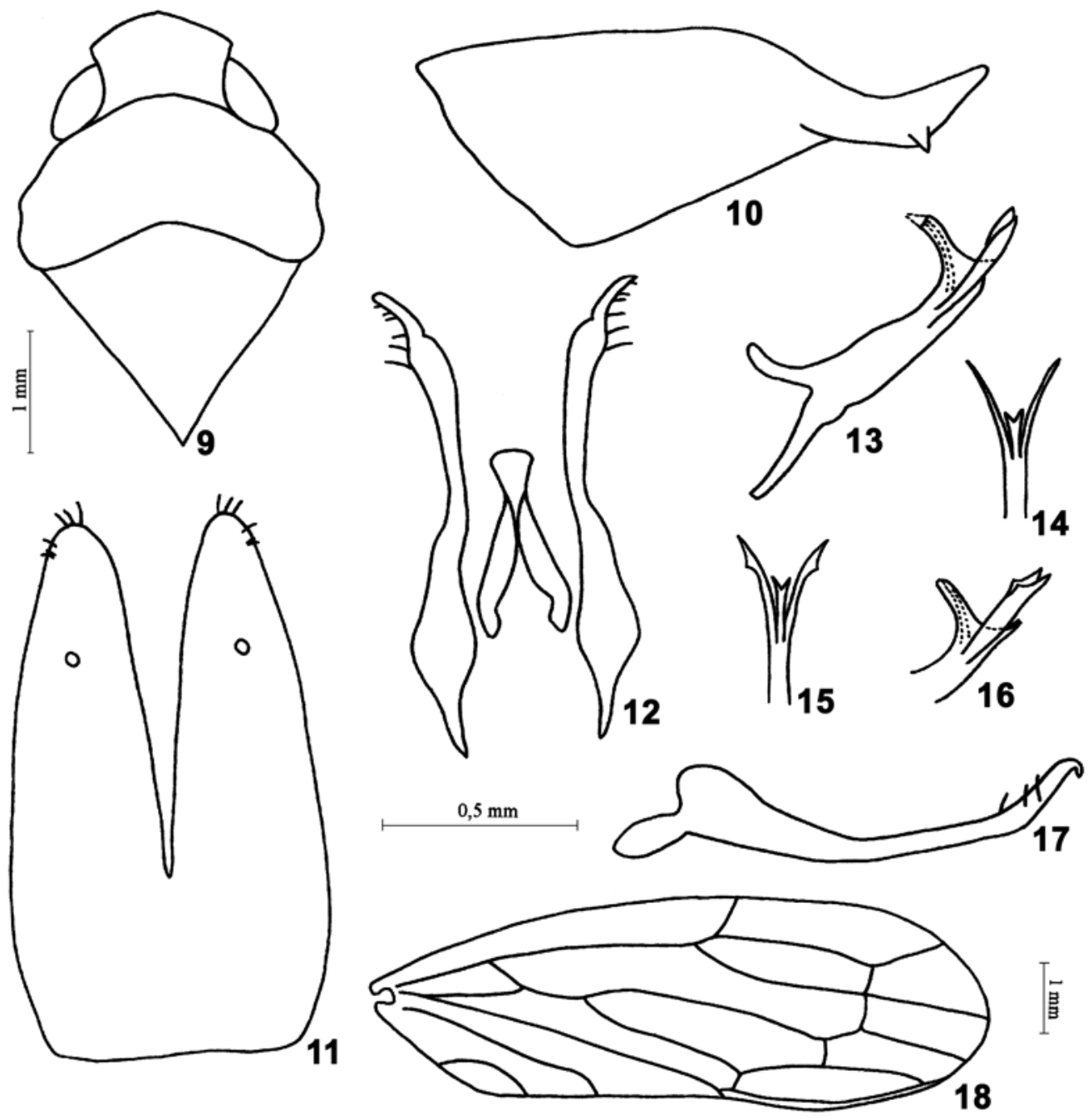

Figs 9-18. Biza ocellata sp. nov.: (9) cabeça, pronoto e escutelo, vista dorsal; (10) placas subgenitais, vista ventral; (11) pigóforo, vista lateral; (12) edeago, holótipo, vista lateral; (13) processos lateral e apical do edeago, holótipo, vista dorsal; (14) edeago, parátipo, vista lateral; 15, processos lateral e apical do edeago, parátipo, vista dorsal; (16) estilos e conetivo, vista dorsal; (17) estilo, vista lateral; (18) asa anterior.

\section{Biza ocellata sp. nov. Figs 9-18}

Holótipo macho. Brasil, Amazonas: Coari (Rio Urucu, $4^{\circ} 51^{\prime} 56,5^{\prime \prime}$ - $\left.65^{\circ} \mathrm{W}, 4^{\prime} 56,6^{\prime \prime} \mathrm{W}\right), 11-18 / \mathrm{V} / 1991$, P.F. Bührnheim, N.O. Aguiar \& F.A. Fé leg. [INPA]. Parátipo: Coari (Rio Urucu,

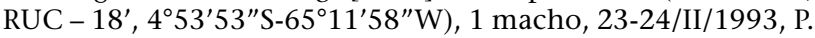
Bührnheim et al. leg. [DZUP].

Diagnose. Edeago com dois processos laterais apicais e ápice bifurcado; pigóforo com dente ventral e ápice afilado e arredondado.

Holótipo macho. Comprimento total 10,32; comprimento mediano da cabeça 0,64 ; distância transocular 1,80; distância interocular 0,88 ; comprimento mediano do pronoto 0,96 ; distância trans-umeral 2,60; largura máxima do escutelo 2,04; comprimento mediano do escutelo 1,92; comprimento das asas anteriores 8,40; largura máxima das asas anteriores 2,20.

Cabeça, em vista dorsal, com comprimento mediano aproximadamente $1 / 3$ da largura transocular; demais características semelhantes à Biza castanea sp. nov.

Asa anterior com venação distinta, com quatro células apicais e três células anteapicais, célula anteapical interna formada pela fusão da veia Média Posterior (MP) com a Cúbito Anterior (CuA). Apêndice curto e estreito estendendo-se até a base da segunda célula apical.

Genitália masculina. Pigóforo com ápice estreito e arre-

Revista Brasileira de Zoologia 20 (2): 231-238, junho 2003 


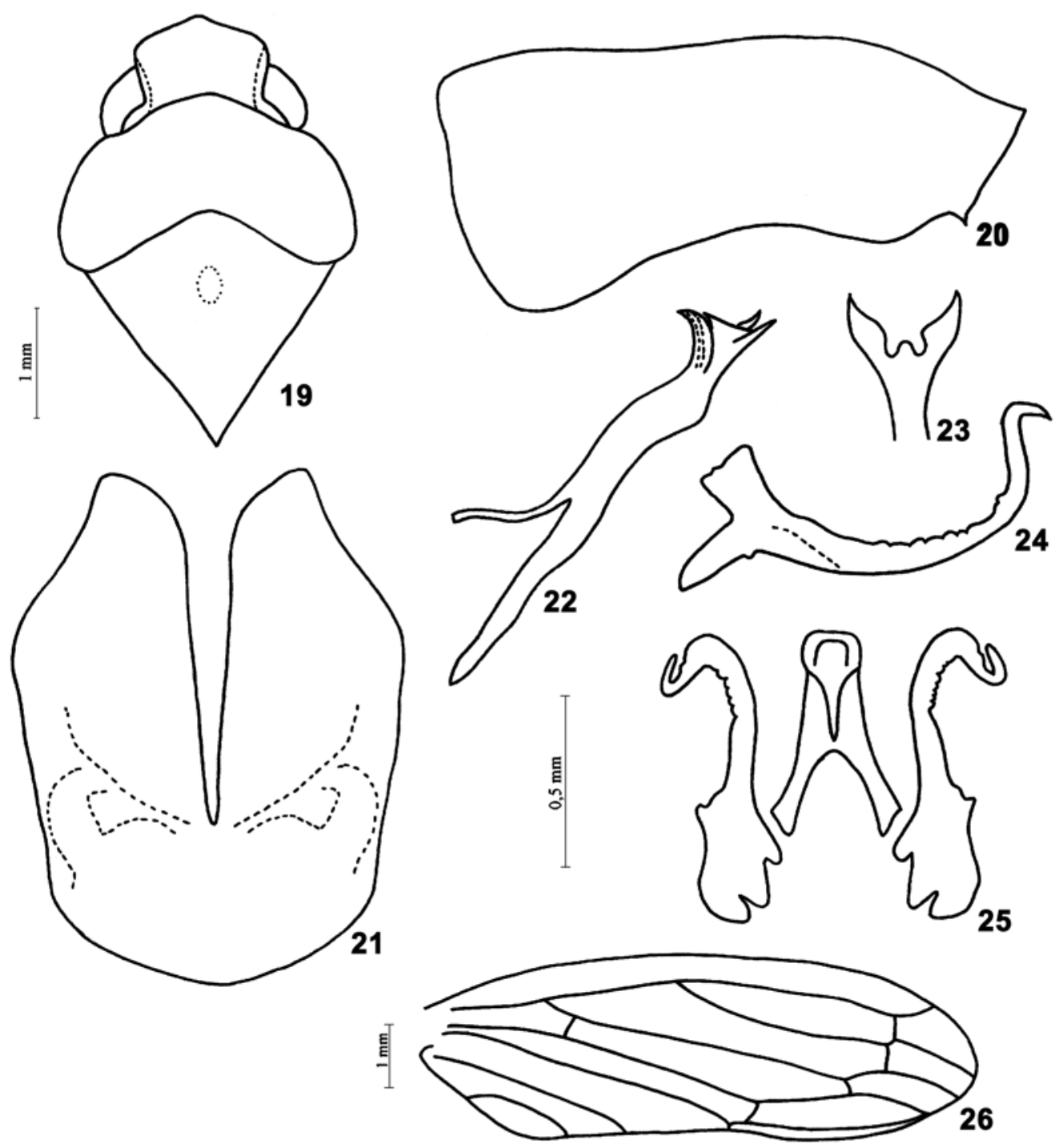

Figs 19-26. Biza similis sp. nov.: (19) cabeça, pronoto e escutelo, vista dorsal; (20) placas subgenitais, vista ventral; (21) pigóforo, vista lateral; (22) edeago, vista lateral; (23) processo lateral do edeago, vista dorsal; (24) estilos e conetivo, vista dorsal; (25) estilo, vista lateral; (26) asa anterior.

dondado, com dente no terço apical da margem ventral. Placas subgenitais fusionadas apenas no terço basal, com microcerdas no ápice e com duas manchas redondas no terço apical. Estilos relativamente compridos com gancho apical, com cerdas no ápice e, em vista lateral, com lobo projetado dorsalmente no terço basal. Conetivo em forma de "Y" invertido. Edeago com uma expansão no terço basal da haste central e antes do ápice ocorre uma curvatura para cima, com um par de processos laterais surgindo no terço apical e um processo apical bifurcado. No holótipo, os ápices do par de processos laterais são pontiagudos, enquanto que no parátipo, os ápices do par de processos laterais são truncados.

Fêmea desconhecida.

Coloração geral amarela. Asas anteriores castanhas com veias marrons.

Comentários. Biza ocellata sp. nov. é semelhante no aspecto geral a $B$. castanea sp. nov., porém difere na forma do pigóforo, o qual é mais arredondado e na forma do edeago, que apresenta, além dos processos laterais que são relativamente mais curtos, um processo apical central bifurcado. Venação das asas anteriores também diferem por apresentar a fusão das veias $\mathrm{MP}$ e CuP. 


\section{Biza similis sp. nov. Figs $19-26$}

Holótipo macho. Brasil, Mato Grosso: Sinop, X/1975, M. Alvarenga leg. [DZUP]. Parátipo: 1 macho, mesmos dados do holótipo. [DZUP]

Diagnose. Edeago com duas pequenas abas laterais no terço basal; pigóforo retangular com dente ventral e ápice truncado.

Holótipo macho. Comprimento total 10,28; comprimento mediano da cabeça 0,68 ; distância transocular 1,92; distância interocular 1,08; comprimento mediano do pronoto 1,00 ; distância trans-umeral 2,76; largura máxima do escutelo 2,16; comprimento mediano do escutelo 2,20; comprimento das asas anteriores 8,60; largura máxima das asas anteriores 2,00.

Cabeça, em vista dorsal, com comprimento mediano aproximadamente $1 / 3$ da largura transocular; demais características semelhantes as duas espécies descritas acima.

Asas anteriores com venação distinta, com quatro células apicais, três células anteapicais, somente a externa fechada. Apêndice estreito e curto estendendo-se até a base da segunda célula apical.

Genitália masculina. Pigóforo retangular com margem apical truncada e com pequeno dente no ápice da margem ventral. Placas subgenitais fusionadas até o terço basal e relativamente larga. Estilos com ápices curvados e terço apical da margem externa enrugada e, em vista lateral, com lobos largos e projetados dorsalmente na base. Conetivo em forma de "Y" invertido. Edeago simples com expansão no terço basal e curvatura apical para região dorsal e com um par de processos laterais no ápice.

Fêmea desconhecida.

Coloração geral amarelada sem marcas contrastantes.

Comentários. Biza similis sp. nov. é similar a B. castanea sp. nov., diferindo na forma do pigóforo, mais retangular, e no edeago, com um par de processos laterais mais curtos e mais largos, em forma de abas.

\section{Biza maculata sp. nov. Figs 27-34}

Holótipo macho. Brasil, Amazonas: Coari (Rio Urucu,

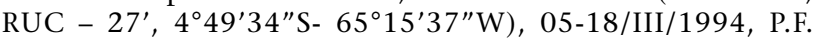
Bührnheim et al. leg. [INPA]. Parátipos. BrasiL, Amazonas: Tefé (locação São Mateus, $4^{\circ} 43^{\prime} 24^{\prime \prime} S-65^{\circ} 40^{\prime} 06^{\prime \prime} \mathrm{W}$ ), 2 machos, 0716/IX/1994, P. Bührnheim et al. leg.; Coari (Rio Urucu, RUC-

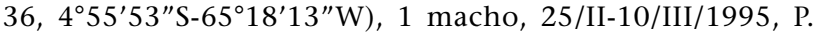
Bührnheim et al. leg.; Juruá (Mineruazinho, 03'34'85"S66 59'15”W), 1 macho, 13-25/01/1996, P. Bührnheim, N. O. Aguiar et al. leg.; Coari (Rio Urucu, prox. IMT-1), 449'33"S6501'49"W), 1 macho, 17-29/IX/1995, P. Bührnheim \& N.O. Aguiar leg. [DZUP].

Diagnose. Cabeça, pronoto e escutelo com algumas manchas marrons dispersas. Asas anteriores com seis máculas pretas junto a margem anal. Edeago simples com dois pequenos espinhos no terço basal; pigóforo com pequeno dente ventral e ápice afilado truncado.

Holótipo macho. Comprimento total 10,60; comprimento mediano da cabeça 0,76 ; distância transocular 1,80; distância interocular 0,96 ; comprimento mediano do pronoto 1,20 ; distância trans-umeral 2,56; largura máxima do escutelo 2,08; comprimento mediano do escutelo 1,60; comprimento das asas anteriores 8,60; largura máxima das asas anteriores 2,80.

Cabeça, em vista dorsal, com comprimento mediano aproximadamente 3/7 da largura transocular; margem anterior arredondada e com carena na transição entre a coroa e a face. Demais características semelhantes as espécies descritas anteriormente.

Asas anteriores com venação distinta. Com quatro células apicais, porém com uma veia extranumerária formando uma célula triangular na margem apical; três células anteapicais, sendo a externa fechada.

Genitália masculina. Pigóforo afilado posteriormente com ápice truncado. Placas subgenitais fusionadas até o terço basal, com microcerdas no ápice e, em vista lateral, com dente apical. Estilos longos, delgados, curvados para fora no ápice. Conetivo em forma de "V" invertido com região central mais esclerotinizada. Edeago simples com expansão no terço basal, curvado para cima no terço apical e com um pequeno par de espinhos no terço apical.

Fêmea desconhecida.

Coloração geral castanha. Cabeça, pronoto e escutelo com algumas manchas marrons dispersas. Asas anteriores amarelas, quase laranja, exceto apicalmente, que se apresentam translúcidas; veias marrons; com uma mancha marrom no ápice do clavo e base da primeira célula apical.

Comentários. Há duas variações observadas nos parátipos de Biza macullata sp. nov. em relação ao holótipo. Nos parátipos, as asas anteriores não apresentam a veia extranumerária que forma uma célula triangular na margem apical, porém apresentam três manchas marrons, uma na base do clavo, outra sobre a Anal 1 junto à margem anal e a terceira no ápice do clavo e base da primeira célula apical, mesma posição encontrada no holótipo. Biza macullata sp. nov. é semelhante a B. craspa Kramer, 1962, diferindo, além da coloração, no pigóforo mais afilado e edeago com um par de curtos espinhos no terço apical.

\section{Biza trimaculata sp. nov. Figs 35-41}

Holótipo macho. Brasil, Amazonas: Coari (Rio Urucu,

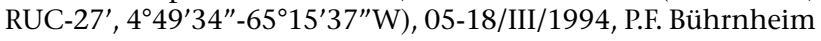
et al. leg. [INPA].

Diagnose. Coloração geral amarelada pálida com manchas alaranjadas no pronoto e escutelo e três manchas marrons na margem posterior do pronoto. Edeago simples, sem processos; pigóforo com dente ventral e ápice afilado arredondado.

Holótipo macho. Comprimento total 8,64; comprimento mediano da cabeça 0,64 ; distância transocular 1,64; distância interocular 0,88 ; comprimento mediano do pronoto 0,88 ; distância trans-umeral 2,20; largura máxima do escutelo 1,92; comprimento mediano do escutelo 1,60; comprimento das asas anteriores 7,08; largura máxima das asas anteriores 2,20.

Cabeça, em vista dorsal, com comprimento mediano aproximadamente $2 / 5$ da largura transocular; margem anterior arredondada, com carena na transição entre a coroa e a face; superfície levemente pontuada. Demais características como nas descrições anteriores. 


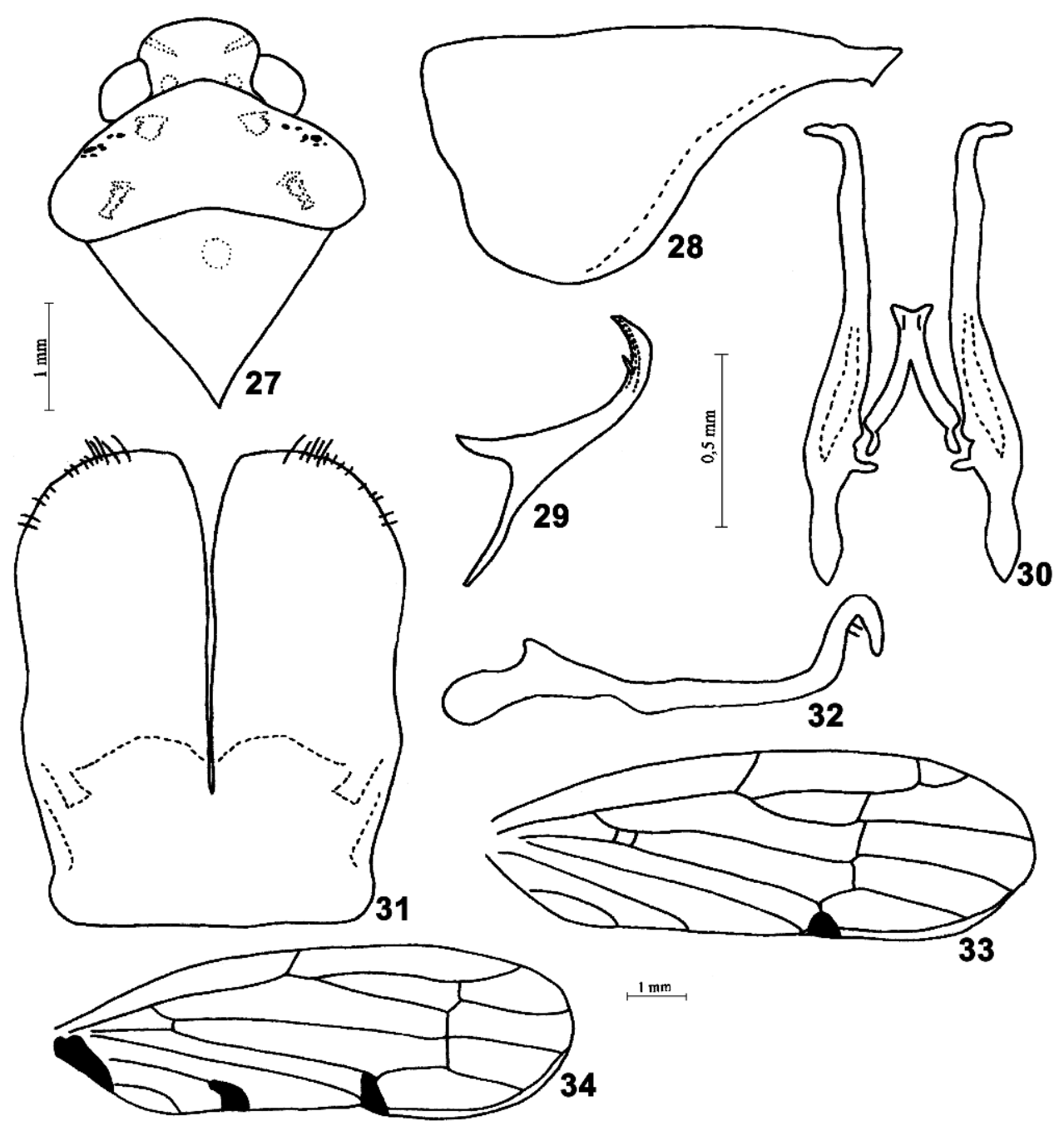

Figs 27-34. Biza maculata sp. nov.: (27) cabeça, pronoto e escutelo, vista dorsal; (28) placas subgenitais, vista ventral; (29) pigóforo, vista lateral; (30) edeago, vista lateral; 31, estilos e conetivo, vista dorsal; (32) estilo, vista lateral; (33) asa anterior, holótipo; (34) asa anterior, parátipo.

Asas anteriores com venação distinta, com quatro células apicais e três células anteapicais, célula anteapical mediana aberta.

Genitália masculina. Pigóforo aproximadamente triangular com margem posterior arredondada e com dente na margem ventro-apical. Placas subgenitais fusionadas até o terço basal e, em vista lateral, com dentes apicais. Estilos longos e delgados, curvados para dentro no ápice e, em vista lateral, sem lobo projetado dorsalmente. Conetivo em forma de " $\mathrm{Y}$ " invertido, carenado medianamente. Edeago simples, relativamente curto, delgado, sem processos, com projeção dorsal na base e fortemente curvado no ápice.

Fêmea desconhecida.

Coloração geral amarelada pálida, com manchas alaran- jadas no pronoto e escutelo e pronoto com três manchas marrons na margem posterior. Asas anteriores amarelo-pálidas, hialinas, com veias amareladas, exceto as apicais que são castanhas.

Comentários. Biza trimaculata é similar a B. craspa Kramer, 1962, diferindo além da coloração, na forma do pigóforo, mais afilado, e do edeago, com um par de espinhos apicais.

\section{AGRADECIMENTOS}

Agradecemos ao Conselho Nacional de Desenvolvimento Científico e Tecnológico (CNPq), pelo auxílio concedido referente ao processo 475565/01-0, bolsa de mestrado e Produtividade em Pesquisa. 




Figs 35-41. Biza trimaculata sp. nov.: (35) cabeça, pronoto e escutelo, vista dorsal; (36) placas subgenitais, vista ventral; (37) pigóforo, vista lateral; (38) edeago, vista lateral; (39) estilos e conetivo, vista dorsal; (40) estilo, vista lateral; (41) asa anterior.

\section{REFERÊNCIAS BIBLIOGRÁFICAS}

Chiamolera, L. DE B. \& R.R. Cavichioli. 1999. Biza sinopensis sp. n. (Hemiptera, Auchenorrhyncha, Neocoelidiinae) do Mato Grosso, Brasil. Revista Brasileira de Zoologia, Curitiba, 17 (1): 61-63.

Hamilton, K.G.A. 1981. Morphology and evolution of the rhynchotan head (Insecta: Hemiptera, Homoptera). Canadian Entomologist, Ottawa, 113 (11): 953-974.

Kramer, J.P. 1958. Six new species of Chinaia from Central America (Homoptera: Cicadellidae). Proceedings of the Biological Society of Washington, D.C., 71: 69-74.

. 1959. An elucidation of the Neotropical genus Chinaia with a key to males and a new allied genus
(Homoptera: Cicadellidae: Neocoelidiinae). Proceedings of the Biological Society of Washington, D.C., 72: 23-32.

. 1961. New Venezuelan leafhoppers of the subfamilies Xestocephalinae and Neocoelidiinae (Homoptera: Cicadellidae). Proceedings of the Biological Society of Washington, D.C., 74: 235-240.

. 1962. Biza Walker: A synopsis of Biza and a new allied genus (Homoptera: Cicadellidae: Neocoelidiinae). Proceedings of the Biological Society of Washington, D.C., 75: 101-106.

1964. A generic revision of the leafhopper subfamily Neocoelidiinae. (Homoptera: Cicadellidae). Proceedings of the National Museum, D.C., 115 (3484): 259-287.

. 1967. New Neotropical Neocoelidiinae with keys to

Revista Brasileira de Zoologia 20 (2): 231-238, junho 2003 
the species of Coelidiana, Xenocoelidiana, and Nelidina (Homoptera: Cicadellidae). Proceedings of the Entomological Society of Washington, D.C., 69 (1): 31-46.

Kramer, J.P. \& R. Linnavuori, 1959. A new genus and two new species of leafhoppers from South America (Homoptera: Cicadellidae: Neocoelidiinae). Proceedings of the Biological Society of Washington, D.C., 72: 55-58.

Mejdalani, G.L.F. 1998. Morfologia externa dos Cicadellinae (Homoptera: Cicadellidae): Comparação entre Versigonalia ruficauda (Walker) (Cicadellini) e Tretogonia cribrata (Melichar) (Proconiini), com notas sobre outras espécies e análise da terminologia. Revista Brasileira de Zoologia,
Curitiba, 15 (2): 451-544.

Nielson, M.W. \& W.J. KNight 2000. Distributional patterns and possible origin of leafhoppers (Homoptera, Cicadellidae). Revista Brasileira de Zoologia, Curitiba, 17 (1): 81-156.

OMAN, P.W. 1943. A generic revision of the Neartic Cicadellidae. Summary of doctoral thesis, George Washington University. - 1949. The Nearctic leafhoppers (Homoptera: Cicadellidae). A generic classification and check list. Memoirs of the Entomological Society of Washington, D.C., 3: 1-253.

WALKER, F. 1858. List of the specimens of Homopterous insects in the collection of the British Museum Suppl., p. 1-307.

Recebido em 04.XI.2002; aceito em 13.V.2003.

Revista Brasileira de Zoologia 20 (2): 231-238, junho 2003 